Full Length Article

\title{
Ultrafast gas chromatographic method for quantitative determination of total FAMEs in biodiesel: An analysis of $90 \mathrm{~s}$
}

\author{
Antonio Carlos Bergamaschi Tercini ${ }^{\mathrm{a}}$, Murilo Pinesi ${ }^{\mathrm{a}}$, Gabrielle Cyntia Calera ${ }^{\mathrm{a}}$, Rodrigo Sequinel ${ }^{\mathrm{a}}$, \\ Rafael Rodrigues Hatanaka ${ }^{\mathrm{a}}$, José Eduardo de Oliveira ${ }^{\mathrm{a}}$, Danilo Luiz Flumignan ${ }^{\mathrm{a}, \mathrm{b}, *}$ \\ ${ }^{a}$ UNESP - São Paulo State University, Institute of Chemistry, Center for Monitoring and Research Quality of Fuels, Biofuels, Petroleum and Derivatives - CEMPEQC, Rua \\ Prof. Francisco Degni, 55, Quitandinha, 14800-900 Araraquara, SP, Brazil \\ b IFSP - São Paulo Federal Institute of Education, Science and Technology - Campus Matão, Rua Stefano D'Avassi, 625 - Nova Cidade, 15991-502 Matão, SP, Brazil
}

\section{A R T I C L E I N F O}

\section{Keywords:}

Biodiesel

Ultrafast gas chromatography

FAMEs

Quality control

\begin{abstract}
A B S T R A C T
Several physicochemical parameters must be determined in order to verify the quality of commercial biodiesel, and the analysis of total fatty acid methyl esters (FAMEs) is the main parameter. Therefore, an efficient and alternative analytical method using gas chromatography coupled with ultrafast module is important. This method was developed to quantify FAMEs in biodiesel commercial samples that originated from different feedstock (babaçu, coconut, rapeseed, corn, soybean, animal/palm oil and sunflower). The chromatographic run time is $90 \mathrm{~s}$. When compared with the official methods, we had a much faster one, which provided an analytical frequency of up to 205 samples a day. This analytical method has been validated according to in-house validation parameters, such as linearity, repeatability, reproducibility (intermediate precision) and accuracy. Two analytical curves were prepared, one for determinate long carbon chain FAMEs (C16-C24) and another for short carbon chain FAMEs (C6-C14). The coefficient of determination (which represents the percentage of the data that is closest to the line of best fit) was 0.9992 for the C18 curve (long chain) and the C12 curve (short chain). Repeatability and reproducibility presented a relative standard deviation of $0.75 \%$ and $1.68 \%$ for the C18 curve and $0.44 \%$ and $1.05 \%$ for the C12 curve, respectively. The accuracy had a standard error of 0.2 for soybean biodiesel, 0.4 for animal/palm commercial biodiesel and 0.2 for babaçu biodiesel.
\end{abstract}

\section{Introduction}

The growing demands for automotive fuels coupled with the economics and environmental problems motivate the search for alternative routes for energy production. In this context, biofuels arise as viable options, being defined as: alternative fuels obtained from renewable sources, technically plausible, economically competitive, immediately available and environmentally acceptable. Biodiesel, especially, has its participation in the energetic world matrix growing frequently $[1,2]$.

Biodiesel is constituted by fatty acid alkyl esters (FAAEs) obtained from transesterification and/or esterification of triglycerides present in vegetable oils and/or animal fats with methanol and/or ethanol. On January 13, 2005, biodiesel was introduced into the Brazilian energy matrix by Law 11097, thus the necessity to control its quality, logistic and marketing as well. Biodiesel quality is provided by the determination of several physicochemical characteristics, established by several specifications. In Brazil, these specifications are set by the Agência Nacional do Petróleo, Gás Natural e Biocombustíveis (ANP), through
Resolution ANP n. 45. In the United States and Europe, such specifications are set by the American Society for Testing and Materials (ASTM) and European Committee for Standardisation (EN), through standards ASTM D6751 and EN 14214 [3].

FAMEs analysis is the main physicochemical characteristic that should ensure the marketed biodiesel quality. In quality control, the determination of the FAMEs profile content is a key parameter and its content is expressed as a mass fraction in percentage. The total FAME content should be greater than $96.5 \%$. FAMEs determination is done according to standards EN 14103 [4] or ABNT NBR 15764 [5]. EN 14103 is the European standard for determining the total content of FAMEs, while ABNT NBR 15764 is the Brazilian standard. In Brazil, both standards are recognized by ANP as reliable methods for total FAMEs. Both standards use conventional gas chromatography (GC) as an analytical technique and take approximately $30 \mathrm{~min}$ in their analyses $[4,5]$.

The ABNT NBR 15764 method specifies the total FAMEs content with carbon chains between C8:0 and C24:0 in biodiesel using an

\footnotetext{
* Corresponding author at: UNESP - São Paulo State University, Institute of Chemistry, Center for Monitoring and Research Quality of Fuels, Biofuels, Petroleum and Derivatives CEMPEQC, Rua Prof. Francisco Degni, 55, Quitandinha, 14800-900 Araraquara, SP, Brazil.

E-mail address: dlflumig@yahoo.com.br (D.L. Flumignan).
} 
external analytical curve. However, this method has a limitation because it uses chloroform as a solvent in sample preparation [4]. Conversely, EN 14103 determination and calculation of FAMEs content is achieved with the response of a single internal standard. In version EN 14103:2003, the range of FAMEs is set from C14:0 (methyl myristate) to $\mathrm{C} 24: 1$ (methyl nervonate) using methyl heptadecanoate (C17:0) as an internal standard. Version EN 14103:2011 extends the carbon chains range from C6:0 to C24:1 and employs methyl nonadecanoate (C19:0) as an internal standard in order to analyze FAMEs of animal origin since animal fat can contain higher C17:0 levels [5].

The demand for biodiesel quality analyses accompanies its growth in the international market. It is therefore important to develop analytical methods that are increasingly faster and more reliable. The present work envisions ultrafast gas chromatography coupled with flame ionization detector (UFGC-FID) as an alternative, a more efficient and appropriate technique to be used in routine analyses of quality control laboratories.

The UFGC system contains a greater number of innovations compared to conventional gas chromatography (GC), i.e.: smaller internal diameter and column length, and higher heating rate in the temperature column. The high-speed analysis was provided by directly resistive heated column in a modular system. All these factors cause the organic compounds to volatilize more rapidly in order to get a faster analysis; i.e., in a few minutes or less [6,7]. Literature has shown that the use of this technique reduces the chromatographic run time in matrix such as gasoline fuel, essential oils, fresh and frozen pork, tea and others [8-12].

Biodiesel is a consolidated product in the Brazilian market, and the amount of research involving biodiesel and its analysis shows the global importance of this product. Taking chromatography as the main FAMEs determination analysis technique for biodiesel samples has led to some authors worrying about the betterment of conditions and the shortening of the analysis time $[13,14]$.

The objective of the present study is the development of an ultrafast gas chromatography method for quantification of FAMEs in pure biodiesel and in biodiesel blends, originated from different feedstocks (babaçu, coconut, rapeseed, corn, soybean, animal/palm and sunflower). To demonstrate the suitability of the proposed method, results obtained after analyzing the certified reference materials SRM 2772 (soy-based) and commercial blend biodiesel samples are presented. These results provide the application of UFGC into routine analyses of biodiesel in quality control.

\section{Materials and methods}

\subsection{Chemicals and reagents}

A $10 \%(\mathrm{w} / \mathrm{w})$ heptane mix solution of each of the 19 standards (C6:0-C24:1) was produced using FAME standards of saturated and unsaturated carbon chains provided by Nu-Check (Elysian, MN, USA) and Sigma-Aldrich (St. Louis, MO, USA). Standard FAMEs were methyl hexanoate (C6:0), methyl octanoate (C8:0), methyl decanoate (C10:0), methyl undecanoate (C11:0), methyl dodecanoate (C12:0), methyl tetradecanoate (C14:0), methyl hexadecanoate (C16:0), methyl palmitoleate (C16:1), methyl octadecanoate (C18:0), methyl oleate (C18:1), methyl linoleate (C18:2), methyl linolenate (C18:3), methyl nonadecanoate (C19:0), methyl eicosanoate (C20:0), methyl docosanoate (C22:0), methyl erucate (C22:1), methyl tetracosanoate (C24:0) and methyl nervonate (C24:1), all within $99.0 \%$ of purity.

The FAMEs standard solutions (used to build the analytical curve) were diluted in heptane for UFGC analyses and chloroform for ABNT NBR 15764. Biodiesel samples were diluted in ethanol for ABNT NBR 15764. Heptane and chloroform were purchased from Vetec Química Fina (Duque de Caxias, RJ, Brazil) and ethanol from SigmaAldrich (St. Louis, MO, USA), all within $99.5 \%$ p.a. The certified reference material (CRM) NIST (SRM 2772) B100 biodiesel soy-based (Gaithersburg, MD,
Table 1

Transesterification reaction conditions of different feedstocks.

\begin{tabular}{lllll}
\hline Raw material & Temperature $\left({ }^{\circ} \mathrm{C}\right)$ & $\begin{array}{l}\text { Catalyst } \\
\text { concentration } \\
(\% \mathrm{w} / \mathrm{w})\end{array}$ & $\begin{array}{l}\text { Molar rate } \\
(\mathrm{Oil}: \mathrm{MeOH})\end{array}$ & $\begin{array}{l}\text { Reaction } \\
\text { time (min) }\end{array}$ \\
\hline Coconut & 40 & 1 & $1: 6$ & 60 \\
Babaçu & 40 & 1 & $1: 6$ & 60 \\
Canola & 40 & 1 & $1: 6$ & 60 \\
Sunflower & 40 & 1.5 & $1: 6$ & 60 \\
Corn & 40 & 1 & $1: 6$ & 120 \\
\hline
\end{tabular}

USA) was used for validation purposes. The FAMEs contents in the CRM are given as certified concentration for eight compounds (C14:0, C16:0, $\mathrm{C} 16: 1, \mathrm{C} 18: 0, \mathrm{C} 18: 1, \mathrm{C} 18: 1, \mathrm{C} 18: 2$ and $\mathrm{C} 20: 0)$ and as reference values for other four (C15:0, C17:0, C18:3 and C22:0).

Hydrogen gas, nitrogen gas and synthetic air gas were provided by White Martins Gases Industriais (Sertãozinho, SP, Brazil), all within a minimal purity of $99.999 \%$.

\subsection{Biodiesel samples}

Five biodiesel samples of different vegetable-based feedstock were investigated. These samples were obtained by transesterification reaction of refined oils of coconut, babaçu, canola, sunflower and corn, bought at supermarket, with methanol using $\mathrm{KOH}$ as catalyst. Table 1 shows transesterification conditions used for each raw-material.

The soybean biodiesel was a NIST CRM 2772 certified reference material. Additionally, a blend commercial biodiesel sample (constituted by $70 \%$ bovine tallow and $30 \%$ palm oil) provided by a JBS S/A biodiesel producer was also analyzed.

\subsection{Standard solutions and biodiesel sample preparations}

All working standard solutions were prepared in a gravimetric dilution in ethanol for GC-FID ABNT NBR 15764 and n-heptane for UFGC analyses. Biodiesel samples were prepared in a gravimetric dilution in chloroform for GC-FID ABNT NBR 15764 and n-heptane for UFGC analyses. Biodiesel samples dilution was ca. 1:70 in UFGC and 1:100 in ABNT NBR 15764. Preparation step was performed as $0.1 \mathrm{~g}$ of biodiesel sample using $20 \mathrm{~mL}$ vials and analytical balance (Ohaus, Adventure series, max. $210 \mathrm{~g}$ ). Total FAMEs concentration was expressed in weight percentage $(\% \mathrm{w} / \mathrm{w})$. Standard solutions concentration is based on the total FAMEs expected in commercial biodiesel samples.

In the ABNT NBR 15764 analyses, two analytical curves were constructed with three standard solutions from 60 to $90(\% \mathrm{w} / \mathrm{w})$ and using ethanol as solvent. One analytical curve (C18 curve) was used for determination and quantification of long carbon chain FAMEs (C16-C24) and another (C12 curve) for short carbon chain FAMEs (C6-C14).

In the UFGC analyses, two analytical curves were constructed with six standard solutions with concentrations ranging from 20 to 100 (\% $\mathrm{w} / \mathrm{w}$ ). One analytical curve (C18 curve) was used for determination and quantification of long carbon chain FAMEs (C16-C24) and another (C12 curve) for short carbon chain FAMEs (C6-C14). Standard solutions dilution is shown in Table 2.

\subsection{GC-FID analyses}

Parallel FAMEs analysis was performed by using a GC-2010 Plus gas chromatograph (Shimadzu Corporation, Kyoto, Japan) equipped with a flame ionization detector (FID) and on-column injector. Separations were performed in a ZB-5HT column (5\% phenyl and $95 \%$ dimethylpolysiloxane, $30 \mathrm{~m} \times 0.32 \mathrm{~mm}$ ID $\times 0.1 \mu \mathrm{m}$ ) provided by Phenomenex. Data was processed with a GCSolution Version 2.0 data system.

Experimental conditions and oven program are those indicated in 
Table 2

Analytical curve preparation for UFGC method.

\begin{tabular}{llll}
\hline Point & Concentration (\% w/w) & $\begin{array}{l}\text { C12 or C18 standards } \\
(\mathrm{mg})\end{array}$ & $\begin{array}{l}\text { Heptane solvent } \\
(\mathrm{g})\end{array}$ \\
\hline 1 & 20 & 20 & 7.0800 \\
2 & 35 & 35 & 7.0650 \\
3 & 50 & 50 & 7.0500 \\
4 & 65 & 65 & 7.0350 \\
5 & 80 & 80 & 7.0200 \\
6 & 100 & 100 & 7.0000 \\
\hline
\end{tabular}

Table 3

Chromatographic conditions used for FAMEs separation and quantification by UFGC.

\begin{tabular}{llll}
\hline Oven conditions & & & \\
\hline & Rate $\left({ }^{\circ} \mathrm{C} \cdot \mathrm{min}^{-1}\right)$ & Temp $\left({ }^{\circ} \mathrm{C}\right)$ & Hold Time (min) \\
\hline & & 60 & 0.1 \\
Ramp 1 & 300 & 180 & 0.2 \\
Ramp 2 & 500 & 250 & 0.66 \\
Injector & & & \\
\hline Mode & Vol $(\mu \mathrm{L})$ & Temp $\left({ }^{\circ} \mathrm{C}\right)$ & Split Ratio \\
\hline Split & 0.5 & 250 & $1: 100$ \\
Detector & & & \\
\hline Temp $\left({ }^{\circ} \mathrm{C}\right)$ & Flow $(\mathrm{mL} / \mathrm{min})$ & & Makeup $\left(N_{2}\right)$ \\
\hline 260 & Air & $H_{2}$ & 30 \\
\hline
\end{tabular}

the ABNT NBR 15764 standard method [4]. Programming chromatographic temperature was set at the initial temperature of $50^{\circ} \mathrm{C}$ (held for $1 \mathrm{~min}$ ), followed by a heating rate of $15^{\circ} \mathrm{C} \cdot \mathrm{min}^{-1}$ up to $180^{\circ} \mathrm{C}$, heating rate of $7^{\circ} \mathrm{C} \cdot \mathrm{min}^{-1}$ up to $230^{\circ} \mathrm{C}$ and, finally, heating rate of $20^{\circ} \mathrm{C} \cdot \mathrm{min}^{-1}$ up to $380^{\circ} \mathrm{C}$ (held for $10 \mathrm{~min}$ ). Estimate analysis time is $35 \mathrm{~min}$. The injector temperature in tracking oven and detector temperature was set at $380{ }^{\circ} \mathrm{C}$. Sample injection volume was $0.5 \mu \mathrm{L}$.

\subsection{Ultrafast gas chromatographic analyses (UFGC)}

The ultrafast analyses for FAMEs determination were performed using a Trace GC Ultra (Thermo Fisher Scientific Inc.) gas chromatograph equipped with a direct resistively-heated ultrafast module system, a high frequency flame ionization detector (FID with $300 \mathrm{~Hz}$ ), a split/splitless injector and a AS-3000 autosampler. The software ChromQuest 5.0 interfaced with the system to manipulate data. Flame ionization detector (FID) was applied because the detection of organic compounds in complex samples is more effective, sensitive, selective and linear over a wide concentration range. Moreover, this detector has high rates of data acquisition (above $300 \mathrm{~Hz}$ ), which are essential in UFGC analyses.

Separations were performed in a UFGC VF-23MS column $(100 \%$ cyanopropylpolysiloxane, $10 \mathrm{~m} \times 0.15 \mathrm{~mm}$ ID $\times 0.15 \mu \mathrm{m}$ ) provided by Thermo Fisher Scientific. VF-23MS has a high polarity which provides more accurate analysis of very polar analytes [8].

Programming chromatographic temperature was set as initial temperature of $60^{\circ} \mathrm{C}$ (held for $0.1 \mathrm{~min}$ ), followed by a heating rate of $300^{\circ} \mathrm{C} \cdot \mathrm{min}^{-1}$ up to $180^{\circ} \mathrm{C}$ (held for $0.2 \mathrm{~min}$ ) and, finally, heated rate of $500{ }^{\circ} \mathrm{C} \cdot \mathrm{min}^{-1}$ up to $250^{\circ} \mathrm{C}$ (held for $0.66 \mathrm{~min}$ ). The total analyses time is $1.5 \mathrm{~min}(90 \mathrm{~s})$. The injector and detector temperatures were set at 250 and $260^{\circ} \mathrm{C}$, respectively. The detector was used with hydrogen flow rate at $35 \mathrm{~mL} \cdot \mathrm{min}^{-1}$ and synthetic air at $350 \mathrm{~mL} \cdot \mathrm{min}^{-1}$. Hydrogen was used as carrier gas at $1.0 \mathrm{~mL} \cdot \mathrm{min}^{-1}$ and nitrogen was used as auxiliary make-up gas at $30 \mathrm{~mL} \cdot \mathrm{min}^{-1}$. The sample injection volume was $0.5 \mu \mathrm{L}$ in split mode (1:100). Table 3 summarizes the UFGC chromatographic conditions used throughout this study for FAMEs separation and quantification.

\subsection{Quantitative total FAMEs concentration in biodiesel}

For total FAMEs quantifications in GC-FID and UFGC methods it was necessary to provide identification and integration area of FAMEs from C6 to C24:1. In both chromatographic methods, the estimate total FAMEs concentration $(C)$ was provided by Eq. (1), where $A$ is the sum of the FAMEs areas; $b$ is the slope and $a$ is the y-intercept of line of best feet in the analytical curves; $m_{a}$ is the sample weight and $m_{s}$ is the solvent weight (heptane). Results shall be expressed in (\% w/w) with one decimal place.

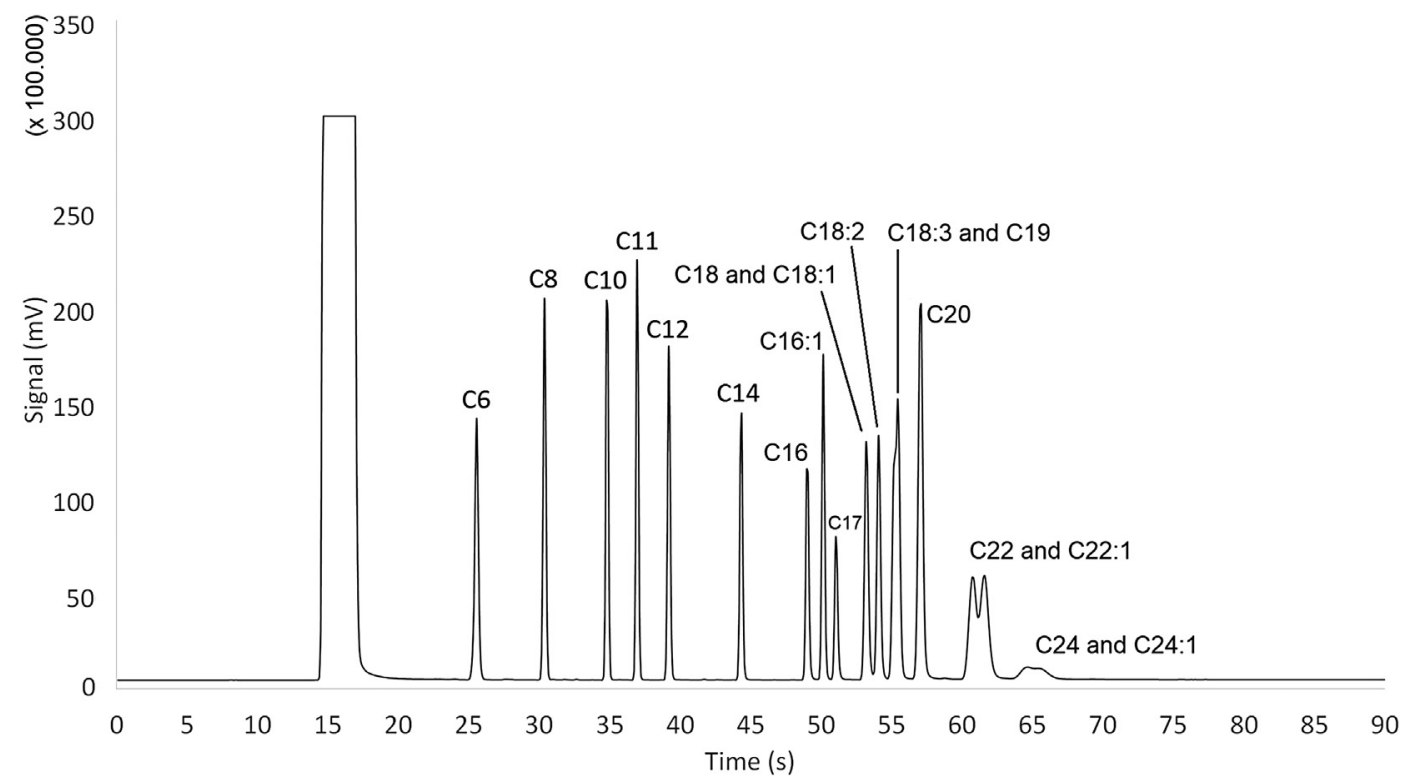

Fig. 1. UFGC chromatographic profile of standards FAMEs mixture (C6:0-C24:1). 


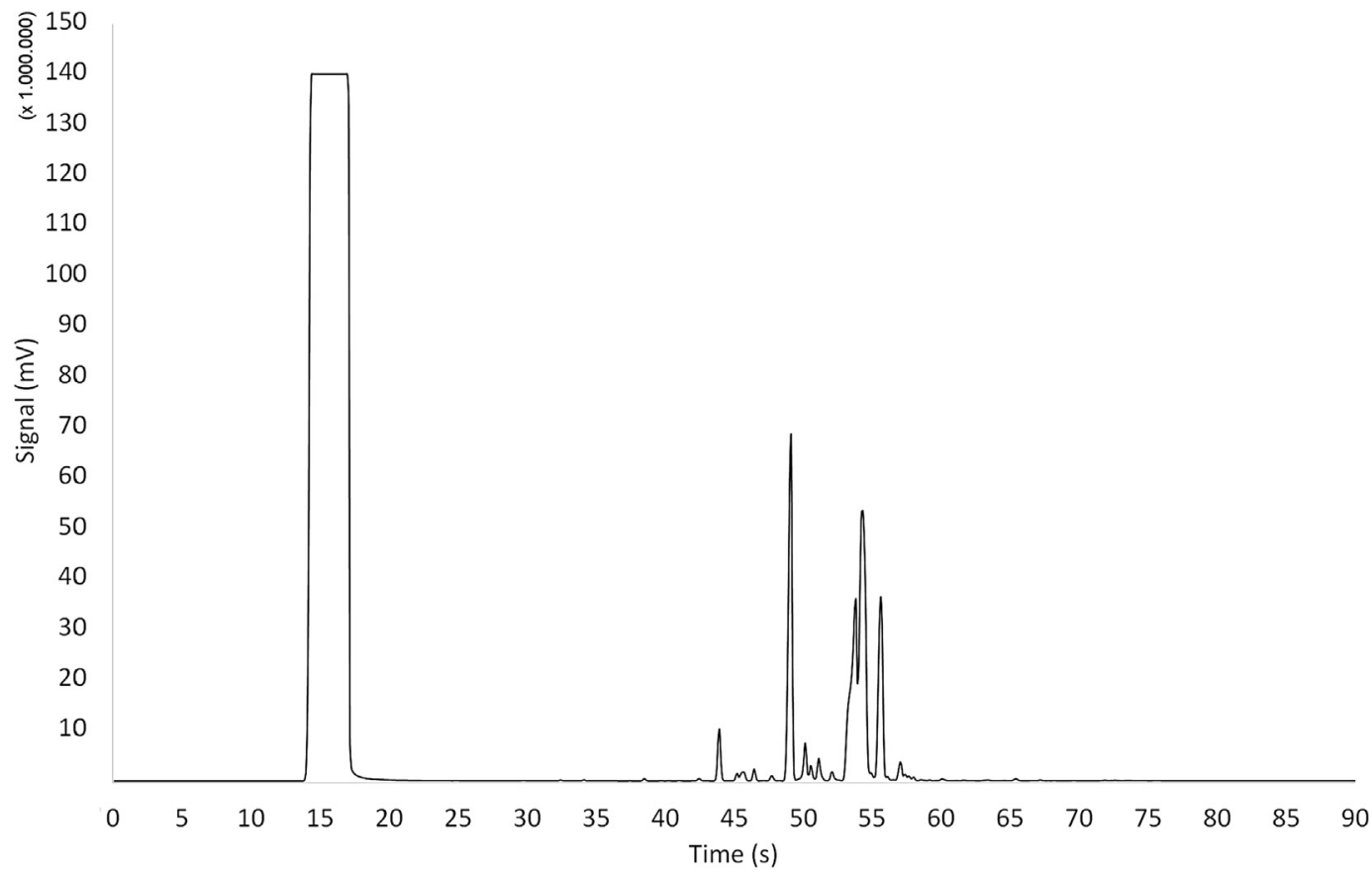

Fig. 2. UFGC chromatographic profile of commercial biodiesel blend sample provided by JBS S/A (constituted by animal and palm-based).

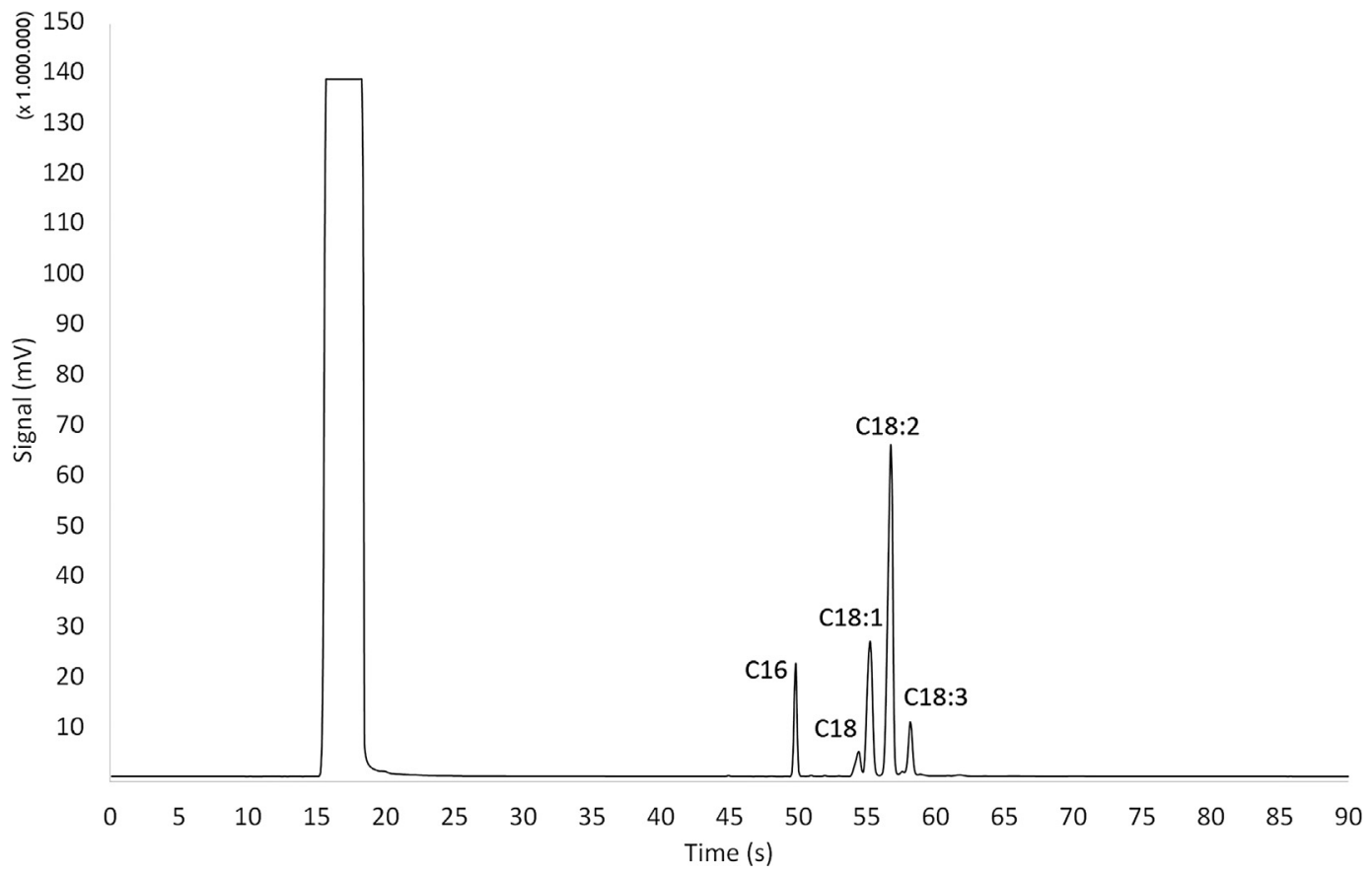

Fig. 3. Chromatogram of the soybean biodiesel (NIST CRM 2772) obtained using UFGC method.

$C=\frac{A-a}{b} \times \frac{m_{s}}{m_{a} \times 70}$

The first part of the equation gives the expected concentration value, and if multiplied by the second part, it adjusts this value by taking into account dilution error in the sample preparation.

\subsection{Ultrafast gas chromatographic analytical validation}

The UFGC analytical method was experimentally developed and validated according to in-house validation parameters, such as linearity, repeatability, reproducibility (intermediate precision) and accuracy.
In linearity, the regression determination coefficients of two analytical curves were evaluated, one for determination of long carbon chain FAMEs (C16-C24) and another for short carbon chain FAMEs (C6-C14). Calibration curves were studied by using six standard solutions with concentration range from 20 to $100(\% \mathrm{w} / \mathrm{w})$. All standard solutions were analyzed in triplicate.

Repeatability was evaluated by analyzing fifteen replicates (15x) of the samples (NIST CRM 2772 for C18 curve and babaçu for C12 curve). Reproducibility (intermediate precision) was verified by triplicate analyzing of the same samples on 5 different days. Both validation parameters were calculated from the relative standard deviation (RSD, expressed as a percentage of the calculated average concentration). 


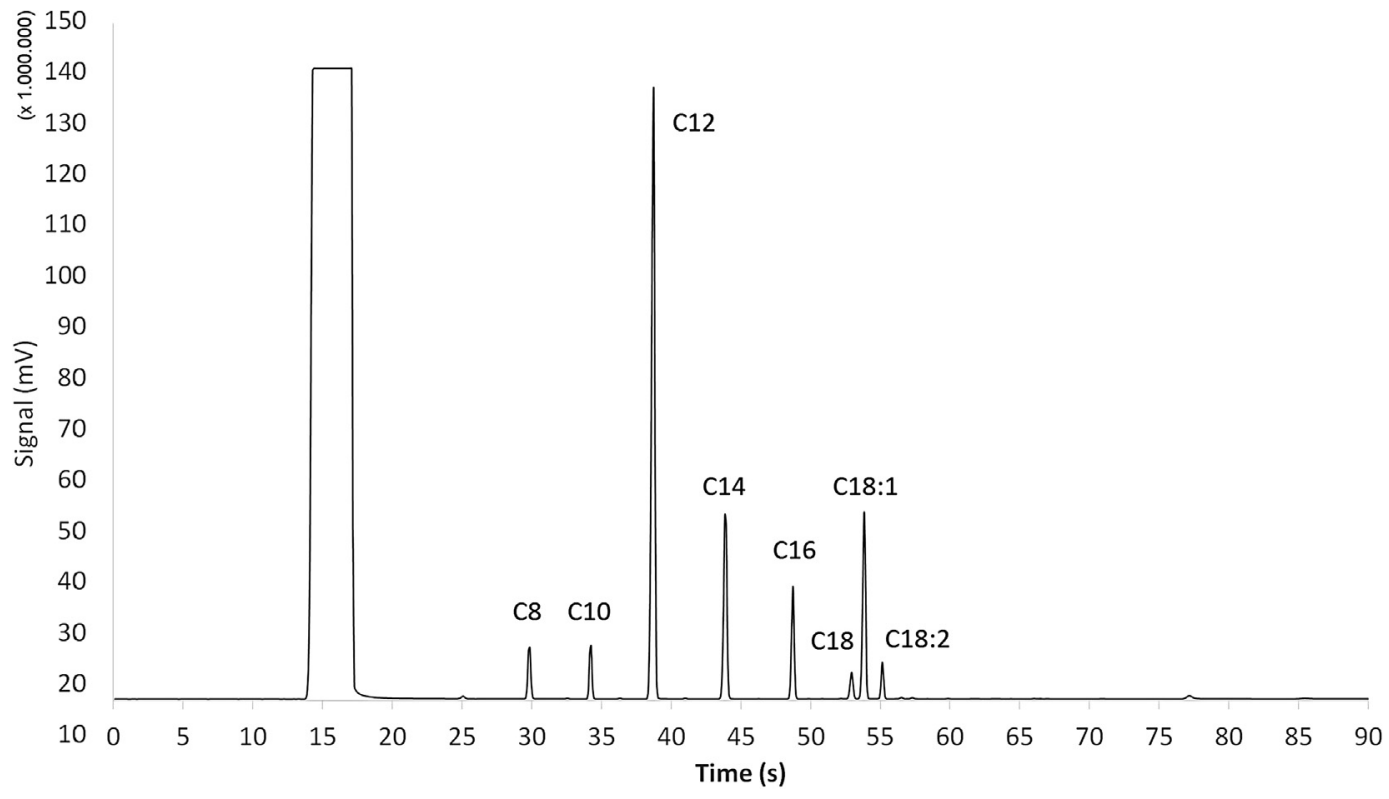

Fig. 4. Chromatogram of the babaçu biodiesel obtained using UFGC method.
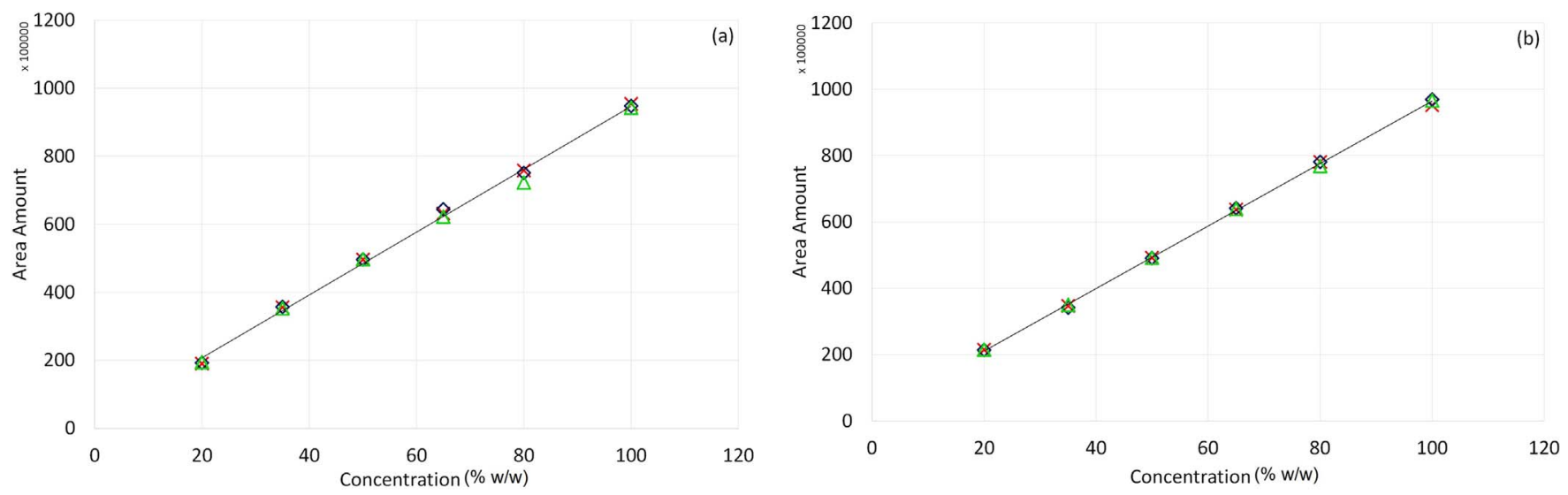

Fig. 5. UFGC Analytical Curves for FAMEs Quantification: (a) C12 curve and (b) C18 curve.

Table 4

C12 and C18 analytical curves in UFGC method and ABNT NBR 15764 curve in conventional GC-FID for FAMEs quantifications by external standard.

\begin{tabular}{lllll}
\hline Analytical curves & Equation & Interval & $\begin{array}{l}\text { Correlation } \\
\text { coefficient }\end{array}$ & RSD \\
\cline { 3 - 5 } & & $(\% \mathrm{w} / \mathrm{w})$ & $\left(R^{2}\right)$ & $(\%)$ \\
\hline $\begin{array}{l}\text { UFGC C12 curve } \\
\text { UFGC C18 curve }\end{array}$ & $\mathrm{y}=934615 \mathrm{x}+2447943$ & $20-100$ & 0.9992 & 0.62 \\
$\begin{array}{l}\text { GC-FID ABNT } \\
\quad \text { NBR 15764 }\end{array}$ & $\mathrm{y}=1082234 \mathrm{x}-7590531$ & $60-90$ & 0.9999 & 0.56 \\
$\quad \begin{array}{l}\text { for C12 } \\
\text { curve }\end{array}$ & & & & \\
$\begin{array}{l}\text { GC-FID ABNT } \\
\quad \text { NBR 15764 }\end{array}$ & $\mathrm{y}=1258707 \mathrm{x}+7535891$ & $60-90$ & 0.9999 & \\
$\quad \begin{array}{l}\text { for C18 } \\
\text { curve }\end{array}$ & & & & 0.29 \\
\hline
\end{tabular}

Accuracy was checked comparing FAMEs quantification in GC-FID (ABNT NBR 15764) and UFGC analyses. Samples analyzed in this validation parameters were NIST CRM 2772, commercial biodiesel (an$\mathrm{imal} / \mathrm{palm}$ oil) and babaçu biodiesel. The first two samples were used to evaluate accuracy of the C18 curve, while the last one was used so for the C12 curve.
Accuracy parameter was calculated by a relative and standard error provided from both quantifications in the UFGC and ABNT NBR 15764 methods (see Eq. (1)), where $R_{\text {exp }}$ is the UFGC results; $V_{\text {ref }}$ is the ABNT NBR 15764 or CRM 2772 reference results; $U_{\text {exp }}$ is the UFGC expanded uncertainty and $U_{\text {ref }}$ is the ABNT NBR 15764 or CRM 2772 expanded uncertainty. This is a statistical way to verify accuracy of new methods [15].

$S E=\frac{R_{\exp }-V_{r e f}}{\sqrt{U_{e x p}^{2}+U_{r e f}^{2}}}$

\section{Results and discussion}

\subsection{Ultrafast gas chromatographic methodology development}

In order to explore the feasibility of the UFGC method for FAMEs determination, initial GC-FID analyses were performed. Section 2.5 and Table 3 summarize the final chromatographic conditions used along this study for FAMEs separation and quantification. GC-FID conditions were selected close to those specified in ABNT NBR 15764. To achieve the conditions established in Section 2.5, many experimental conditions were systematically varied, mainly oven temperature, carrier gas flow, injection volume and split ratio. 
Table 5

UFGC method accuracy.

\begin{tabular}{|c|c|c|c|c|c|c|c|c|c|}
\hline Sample & Feedstocks & $\begin{array}{l}\text { Analytical } \\
\text { curve }\end{array}$ & $\begin{array}{l}\text { UFGC total } \\
\text { FAMEs }(\% \mathrm{w} / \mathrm{w})\end{array}$ & UFGC $U_{\exp }$ & $\begin{array}{l}\text { NIST CRM } \\
\text { value }\end{array}$ & $\begin{array}{l}\text { NBR } 15764 \text { total } \\
\text { FAMEs }(\% \mathrm{w} / \mathrm{w})\end{array}$ & $\begin{array}{l}\text { NIST CRM and } \\
\text { NBR } 15764 U_{\text {ref }}\end{array}$ & $\begin{array}{l}\text { Relative error } \\
(\%)\end{array}$ & Standard error \\
\hline NIST CRM 2772 & Soybean & $\mathrm{C} 18$ & 101.37 & 2.33 & 100.9 & - & 1.33 & 0.5 & 0.2 \\
\hline Commercial JBS & $\begin{array}{l}\text { Animal/Palm } \\
\text { Oil }\end{array}$ & $\mathrm{C} 18$ & 99.94 & 2.33 & - & 98.3 & 3.03 & 1.7 & 0.4 \\
\hline Biodiesel Babaçu & Babaçu Oil & $\mathrm{C} 12$ & 76.42 & 2.33 & - & 76.8 & 3.03 & 0.9 & 0.2 \\
\hline
\end{tabular}

Table 6

Total FAMEs quantification in different biodiesel feedstocks by UFGC method.

\begin{tabular}{lllll}
\hline Samples & Feedstocks & Analytical Curve & Total FAMEs (\% w/w) & UFGC U $\mathrm{U}_{\exp }$ \\
\hline Biodiesel & Coconut & C12 & 95.47 & 2.33 \\
Biodiesel & Corn & C18 & 102.52 & 2.33 \\
Biodiesel & Rapeseed & C18 & 99.43 & 2.33 \\
Biodiesel & Sunflower & C18 & 99.96 & 2.33 \\
\hline
\end{tabular}

The UFGC proposed method (see conditions in Table 3) overcomes the difficulties encountered in standard methods EN 14103 and NBR 15764 to quantify total FAMEs content in biodiesel from different feedstocks. Filho et al. (2012) [16] reported that EN 14103 works in unfavorable chromatographic conditions and in an inadequate internal standard. Moreover, the injector temperature $\left(250^{\circ} \mathrm{C}\right)$ and oven $\left(200{ }^{\circ} \mathrm{C}\right)$ is lower than the volatilization temperature of some esters of long chain fatty acids. Oliveira et al. (2011) [17] show that NBR 15764 using chloroform as a solvent is incompatible with FID, because it causes corrosion during its use and, consequently, loss of its sensitivity. Compounds that contain chlorine atoms in their structure, when burnt in the flame of the detector, produce hydrochloric acid, which promotes corrosion and interferes in the reliability of the results.

The quick chromatogram time for the UFGC analysis is due to the greater number of innovations contained in this system, such as smaller length of column, smaller internal diameter of column, and higher heating rate (column temperature), which provides direct resistive heating of column in a modular system.

To develop a method for quantitative determination of total FAMEs concentration in biodiesel, it is not necessary to achieve the best chromatographic resolution of these compounds, because the quantification is estimated from the sum of the chromatographic peaks areas between C6:0 and C24:1.

Fig. 1 shows the UFGC chromatograms profile obtained for a standard FAMEs mixture in n-heptane and shows the capability of the method to separate C6:0-C24:1 carbons chain. The seventeen FAMEs contained in the standard mixture eluted in less than $90 \mathrm{~s}$, with a retention time of $25 \mathrm{~s}$ for C6:0 and $65 \mathrm{~s}$ for C24:1.

Analyzing a standard FAMEs mixture (Fig. 1), it was observed a coelution between (a) C18:0 and C18:1 in 53 (b) C18:3 and C19:0 in 55 s, (c) C22:0 and C22:1 in 62 s and (d) C24:0 and C24:1 in 65 s. Depending on the feedstock oil, the coelution appeared in biodiesel samples (see commercial biodiesel chromatogram profile in Fig. 2). In these cases, the resolution is not the ideal one for the chromatographic perspective, but it is suitable for the purpose of this work, especially concerning the gain in productivity that comes from the analysis speed.

\subsection{UFGC analytical curves for quantitative total FAMEs}

Quantifications in the UFGC method can be performed by an external calibration method relying on the comparison of the analytes peaks areas with the peaks areas of a series of standards of the compounds of interest at different and known concentration levels. Analytical curves were constructed with six standard solutions with concentrations ranging from 20 to $100(\% \mathrm{w} / \mathrm{w})$.

The UFGC method involves the use of two analytical curves, one using C12 FAMEs as standard and other using C18 FAMEs. Analytical curve (C18 curve) was used for determination and quantification of long carbon chain FAMEs (C16-C24), while (C12 curve) for short carbon chain FAMEs (C6-C14). Therefore, the choice of one of the two curves is required depending on the biodiesel feedstock. In this case, should use C12 curve to quantify biodiesel with FAMEs up to C14:0 carbon chain and C18 curve to quantify biodiesel with FAMEs above C16:0 carbon chain.

Figs. 3 and 4 show chromatograms of soybean (NIST CRM 2772) and babaçu biodiesel samples, used in C18 and C12 analytical curves, respectively. The two analytical curves were necessary because the chromatogram peaks for low molecular weight organic compounds (short carbon chain) have bigger signal intensity than long ones.

The UFGC analysis time is the main advantage of the developed method. Considering the UFGC analysis time, we had a total time of 90 s, $20 \times$ faster than the GC-FID ABNT NBR 15764. This total time provides an analytical frequency of 205 samples a day.

\subsection{Validation parameters in UFGC method}

The performance characteristics of the UFGC-FID method were validated in terms of linearity, repeatability, intermediate precision and accuracy to determine its robustness. Repeatability and intermediate precision were calculated as relative standard deviation (RSD), while accuracy was expressed by relative and standard errors. All validation parameters were obtained under optimized conditions.

\subsubsection{Linearity}

The UFGC analytical curves (Fig. 5) were produced with six standard solutions (20, 35, 50, 70, 85 and $100(\% \mathrm{w} / \mathrm{w})$. A calibration curve of GC-FID ABNT NBR 15764 was also made and produced with three standard solutions $(60,75$ and $90 \% \mathrm{w} / \mathrm{w})$. All standard solutions were performed in triplicate and prepared as described in Section 2.3.

Linearity can be perceived from the good regression determination coefficients $\left(R^{2}\right)$ in all analytical curves (see Table 4). All UFGC analytical curves were linear for FAMEs compounds in several concentration ranges ( $\mathrm{n}=6$ points, see Section 2.3). The determination coefficient $\left(R^{2}\right)$ obtained was 0.9992 from the UFGC C18 and UFGC C12 curves, which is evidence of a good adjustment of the regression model [18].

Relative standard deviation (RSD) of the intercept, calculated from the replicates of the analytical curves, showed variation coefficients lower than $5 \%$ for each concentration. Linear regression, correlation coefficients, interval and relative standard deviation are listed in Table 4. The reason for this comparison of both analytical curves is to show that the regression correlation and slope intercept coefficients were similar, which can bring reliability in FAMEs quantification without problems, regarding any matrix effects. These results indicate that there is no matrix effect in the system.

\subsubsection{Repeatability and reproducibility}

The precision (repeatability and reproducibility) represents an estimate of the variability of measurements done on the same day or during different days [18].

The UFGC method robustness (repeatability and reproducibility) 

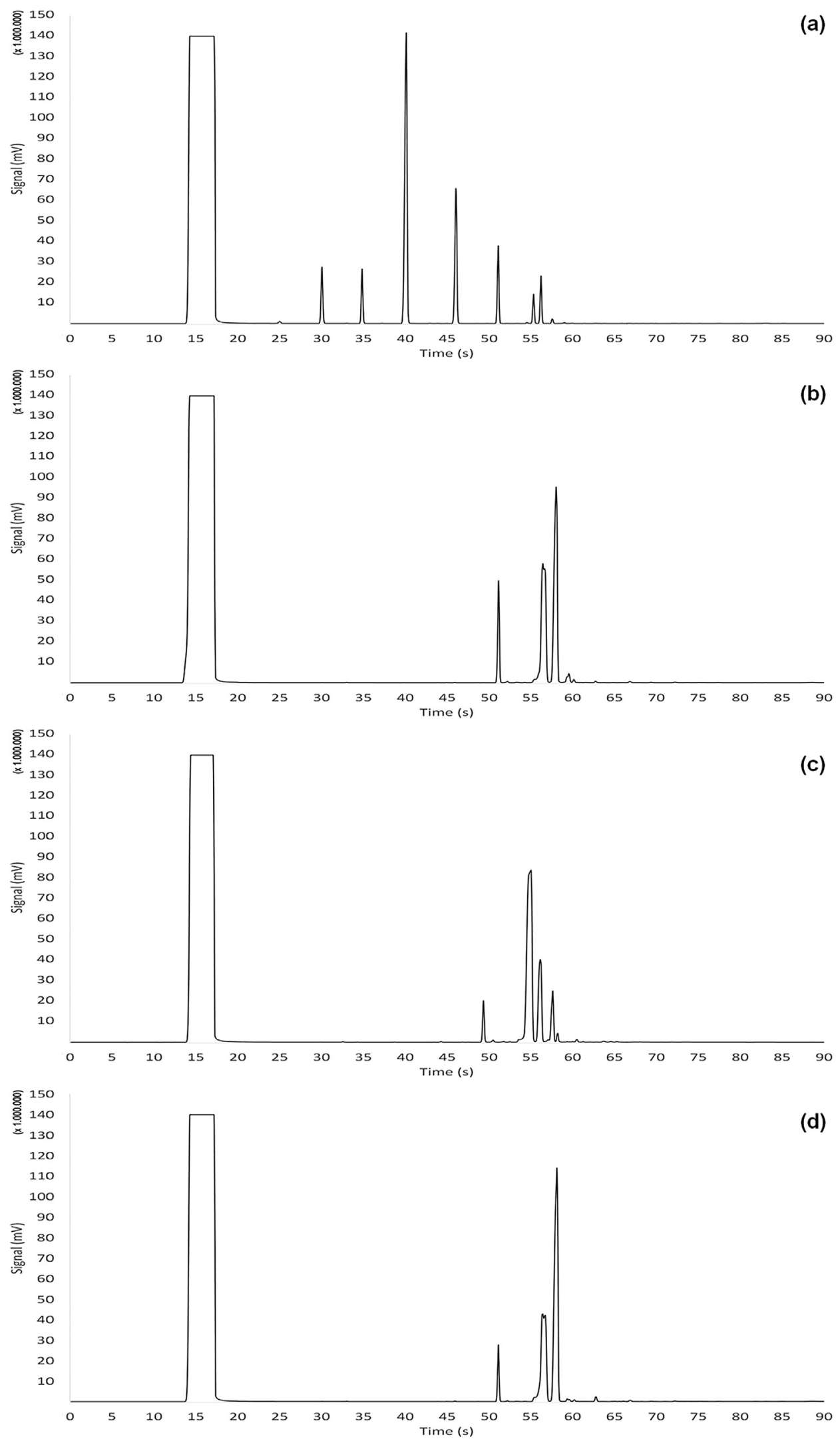

Fig. 6. Chromatograms profiles by UFGC Method: (a) Coconut Biodiesel, (b) Corn Biodiesel, (c) Rapeseed Biodiesel and (d) Sunflower Biodiesel.

was provided through the analyses of the same samples (NIST CRM 2772 biodiesel for C18 curve and babaçu biodiesel for the C12 curve), fifteen (15) times on the same day (similar to intra-day precision) and also 5 times of the same sample on alternate days (similar to inter-day precision), respectively. Robustness was based on the relative standard deviation (RSD).

The repeatability values $\left(R S D_{r}\right.$, intra-day, with 15 replicates) were $0.75 \%$ for the $\mathrm{C} 18$ curve and $0.44 \%$ for the C12 curve, while the 
reproducibility values $\left(R S D_{R}\right.$, inter-day, with 5 replicates) were $1.68 \%$ and $1.05 \%$, respectively. These $R S D_{r}$ and $R S D_{R}$ values are sufficiently small to assure the intra- and inter-day precisions. Therefore, all intraday and inter-day precision results are considered satisfactory [18].

\subsubsection{Accuracy}

The accuracy represents the agreement between the estimated value (obtained through the analytical developed method) and the real value of the substance or accepted as reference (obtained through certificate reference material or standard official methods analysis) [18].

The accuracy was provided for both UFGC analytical curves: C12 and C18 (see Table 5). In the C12 analytical curve, the accuracy was confirmed by the babaçu biodiesel sample, where FAMEs quantification (reference value) was obtained by the ABNT NBR 15764 (as the official method). Babaçu biodiesel feedstock was used because it has mostly low molecular weight FAMEs.

On the other hand, in the C18 analytical curve, the accuracy was confirmed by using two different samples: a) soybean biodiesel certificate reference material (CRM NIST 2772), whose FAMEs quantification was obtained by the UFGC method; and b) commercial biodiesel samples, whose FAMEs quantification (reference value) was obtained by the ABNT NBR 15764 (as official method). Soybean and commercial biodiesel (constituted by animal and palm oil) were chosen as feedstock because they are the most used in Brazilian biodiesel production and the main objective of this method is the application in routine and quality control analysis.

Accuracy parameter was calculated by a standard error (SE) provided from both quantifications in the UFGC and ABNT NBR 15764 methods (see Eq. (2)). The accuracy results (SE $<1$ ) can confirm that the experimental results are suitable to the reference value (see Table 5). In other words, the UFGC and ABNT NBR 15764 feature equivalent FAMEs quantifications [18].

\subsection{Quantitative total FAMEs concentration in biodiesel from different feedstocks by UFGC}

After validation, the FAMEs quantification was determined in biodiesel from different feedstocks (coconut, corn, rapeseed and sunflower) by the UFGC method. Table 6 shows the total FAMEs quantification in these biodiesel samples. For coconut feedstock, the C12 curve was used, while in other feedstocks the C18 curve was.

Fig. 6 shows the UFGC chromatogram profiles of coconut, corn, rapeseed and sunflower biodiesel. Biodiesel from different feedstock was chosen because it is the most important used in Brazilian biodiesel production and the main objective of this method is the application in routine and quality control analysis.

As it can be observed in Table 6, coconut biodiesel sample presented FAMEs content below the minimum level allowed by the Brazilian legislation $(96.5 \% \mathrm{w} / \mathrm{w})$. This biodiesel sample is out of specification and, therefore, considered reproved. All the biodiesel ones are considered approved, because FAMEs content is above the minimum allowed limits in Brazil [3].

\section{Conclusions}

This paper has reported the development and validation of a new and faster method for routine analysis of total FAMEs in commercial biodiesel by UFGC. The UFGC biodiesel profiles showed a satisfactory chromatographic resolution and the analytical validation (linearity, repeatability, reproducibility and accuracy) presented results considered satisfactory.
The proposed method is fast and accurate for the determination of total FAMEs in biodiesel samples of different feedstocks, covered from C6 to C24 and in a concentration range between 20 and 100\% (w/w).

Total FAMEs quantifications by UFGC in commercial biodiesel samples were obtained in high speed ( $90 \mathrm{~s}$ ), which provides an analytical frequency of 205 samples a day. The proposed UFGC method may be considered a potential alternative analytical technique to be used in the evaluation of commercial biodiesel in routine of control analyses in laboratories or in the production process.

\section{Acknowledgements}

The authors would like to thank CNPq (Conselho Nacional de Desenvolvimento Científico e Tecnológico) for the scholarship granted to Antonio Carlos Bergamaschi Tercini, FUNDUNESP (Fundação para o Desenvolvimento da UNESP) for the financial support and also CEMPEQC (Centro de Monitoramento e Pesquisa da Qualidade de Combustíveis, Biocombustíveis, Petróleo e Derivados) for the availability of its laboratories and analytical equipments.

\section{References}

[1] Baptista P, et al. Multivariate near infrared spectroscopy models for predicting the methyl esters content in biodiesel. Anal Chim Acta 2008:607:153-9.

[2] Demirbas A. Fuel alternatives to gasoline. Energy Sour Part B 2007;2:311-20.

[3] Agência Nacional do Petróeo Gás Natural E Biocombustíveis. Resolução ANP nº 45 08/2014. http://nxt.anp.gov.br/NXT/gateway.dll/leg/resolucoesanp/2014/ agosto $/$ ranp $\% 2045 \% 20-\% 202014 . x m l ? f=$ templates $\$ \mathrm{fn}=$ document-frame.htm $\$ 3$. $0 \$ \mathrm{q}=\$ \mathrm{x}=\$ \mathrm{nc}=906$ [accessed 05.04.17].

[4] EN 14103. Fat and oil derivatives-Fatty Acid Methyl Esters (FAME)-Determination of ester and linolenic acid methyl ester contents. London, UK; 2011.

[5] ABNT NBR 15764. Biodiesel-determination of total esters content by gas chromatography. Rio de Janeiro, RJ, Brazil; 2012.

[6] Sequinel R, et al. Ultra fast gas chromatography: an overview of the main parameters, instrumentation and applications. Química Nova 2010;33(10):2226-32.

[7] Thermo Finigan (Italy). Magni P, Zilioli G, Facchetti R. Chromatography column assembly with woven tubular mesh heater element. US 7228067 B2. 29 Oct. 2001, 5 June 2007.

[8] Toscano N, et al. Ultrafast gas chromatographic method for quantitative BTEX determination in commercial gasoline. J Sep Sci 2017;40(7):1508-15.

[9] Bicchi C, et al. Direct resistively heated column gas chromatography (Ultrafast module-GC) for high-speed analysis of essential oils of differing complexities. J Chromatogr A 2004;1024:195-207.

[10] Gorska-Horczyczak E, et al. Chromatographic fingerprints supported by artificial neural network for differentiation of fresh and frozen pork. Food Control 2017;73:237-44.

[11] Kumar S, et al. Non-destructive classification of Assam black tea using ultra-fast gas chromatography (UFGC) coupled with soft independent modeling of class analogy (SIMCA). Sens Transducers 2015;186(3):104-11.

[12] Valloone S, et al. An integrated approach for flavour quality evaluation in muskmelon (Cucumis melo L. reticulatus group) during ripening. Food Chem 2013;139:171-83.

[13] Sobrado LA, et al. Comparison of gas chromatography-combustion mass spectrometry and gas chromatography-flame ionization detector for the determination of fatty acid methyl esters in biodiesel without specific standards. J Chromatogr A 2016;1457:134-43.

[14] Ragonese C, et al. Conventional and fast gas chromatography analysis of biodiesel blends using an ionic liquid stationary phase. J Chromatogr A 2009;1216. 8992-8987.

[15] Agencia Nacional de Vigilancia Sanitaria. Resolução n ${ }^{\circ} 899$ 05/2003. Guia para validação de métodos analíticos e bioanalíticos. http://redsang.ial.sp.gov.br/site/ docsleis/vm/vm1.pdf [accessed 27.05.14].

[16] Filho NRA, et al. Simultaneous gas chromatographic analysis of total esters, mono-, di- and triacylglycerides and free and total glycerol in methyl or ethyl biodiesel. Fuel 2012;96:476-81.

[17] Oliveira JE, et al. EN 14103 adjustments for biodiesel analysis from different raw materials, including animal tallow containing C17. Bioenergy Technol 2011.

[18] Inmetro (2011), National Institute of Metrology, Standardization and Industrial Quality (INMETRO). Guidelines on validation of methods for chemical testing, DOQ-CGCRE-008; 2011. 